\section{National Latinx AIDS Awareness Day - October 15, 2019}

National Latinx AIDS Awareness Day, October 15, is observed each year to focus on the continuing and disproportionate impact of human immunodeficiency virus (HIV) infection and acquired immunodeficiency syndrome (AIDS) on Hispanics/Latinos in the United States. In 2017, 26\% of newly diagnosed HIV infections occurred in Hispanics/Latinos (1). Seventy-five percent of these newly diagnosed HIV infections in Hispanics/ Latinos were in men who have sex with men (MSM), and an additional 3\% were in MSM who inject drugs (1).

An analysis of the behaviors of Hispanic/Latino MSM included in CDC's National HIV Behavioral Surveillance system found that nearly $75 \%$ reported having had condomless anal sex during 2017 (2). However, because some of these MSM reported using preexposure prophylaxis ( $\mathrm{PrEP}$ ), fewer than $60 \%$ of those who were non-U.S.-born and fewer than $50 \%$ of those who were U.S.-born were having unprotected anal sex (2).

National Latinx AIDS Awareness Day is an opportunity to encourage increased HIV prevention efforts among Hispanics/Latinos. CDC supports testing, linkage to and engagement in care and treatment, and other efforts to reduce the risk for acquiring or transmitting HIV infection. More information is available at https://www.cdc.gov/hiv/ group/racialethnic/hispaniclatinos/index.html and https:// www.cdc.gov/hiv/group/msm/hispanic-latino.html.

\section{References}

1. CDC. Diagnoses of HIV infection in the United States and dependent areas, 2017. HIV surveillance report, vol. 29. Atlanta, GA: US Department of Health and Human Services, CDC; 2018. https:// www.cdc.gov/hiv/pdf/library/reports/surveillance/cdc-hivsurveillancereport-2017-vol-29.pdf

2. Trujillo L, Chapin-Bardales J, German EJ, Kanny D, Wejnert C; National HIV Behavioral Surveillance Study Group. Trends in sexual risk behaviors among Hispanic/Latino men who have sex with men-19 urban areas, 2011-2017. MMWR Morb Mortal WklyRep 2019;68:873-9.

\section{Trends in Sexual Risk Behaviors Among Hispanic/Latino Men Who Have Sex with Men - 19 Urban Areas, 2011-2017}

Lindsay Trujillo, $\mathrm{MPH}^{1,2}$; Johanna Chapin-Bardales, $\mathrm{PhD}^{1}$; Emilio J. German, MSHSA ${ }^{1}$; Dafna Kanny, $\mathrm{PhD}^{1}$; Cyprian Wejnert, $\mathrm{PhD}^{1}$; the National HIV Behavioral Surveillance Study Group

Correct and consistent condom use and human immunodeficiency virus (HIV) preexposure prophylaxis (PrEP) are protective against sexual transmission of $\operatorname{HIV}(1,2)$. The incidence of HIV infection among Hispanic/Latino men who have sex with men (MSM) in the United States is increasing (3). HIV risk among Hispanic/Latino MSM differs based on their place of birth and years of U.S. residence (4). Data from CDC's National HIV Behavioral Surveillance (NHBS)* for 2011-2017 were analyzed to assess changes in sexual risk

* NHBS is a cross-sectional biobehavioral surveillance system conducted in urban areas with high HIV prevalence. The number of urban areas participating differs temporally.

\section{INSIDE}

880 Update: Influenza Activity - United States and Worldwide, May 19-September 28, 2019, and Composition of the 2020 Southern Hemisphere Influenza Vaccine

885 Vital Signs: Burden and Prevention of Influenza and Pertussis Among Pregnant Women and Infants United States

893 National Update on Measles Cases and Outbreaks United States, January 1-October 1, 2019

897 Notes from the Field: Environmental Contamination from E-cigarette, Cigarette, Cigar, and Cannabis Products at 12 High Schools - San Francisco Bay Area, 2018-2019

901 QuickStats

Continuing Education examination available at https://www.cdc.gov/mmwr/cme/conted_info.html\#weekly.

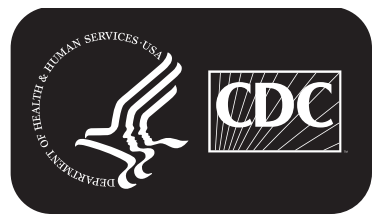

U.S. Department of Health and Human Services Centers for Disease Control and Prevention 